accidents generally it is the man who is tired from long hours of work who is the most prone to take a risk and so suffer an accident. Could this be a significant factor in tractor accidents? The environment of a farm can rarely be changed, but accidents were more common when visibility was poor, when gradients were steep, and when the surface was wet, slippery, or boggy. These conditions are commoner north and west of a line joining the Humber to the Exe than south and east of it.

In the prevention of these injuries, with their high fatality rate, improved design of the vehicle and the safer "packaging " of its occupant would seem to be as important as it is with road vehicles. ${ }^{2}$ Almost all tractors have a high centre of gravity and are prone to overturn. Most have not been designed to protect their driver when this happens. Considerable studies on these problems have been made in Sweden, where standard tests for the strength of the cab are enforced, and similar work is now in progress at the National Institute of Agricultural Engineering at Silsoe in Bedfordshire. Once the cockpit is made more rigid the driver may be well advised to wear a simple lap harness to prevent his being thrown about in the cab or ejected and subsequently crushed.

\section{Pesticides in the Body}

In this week's issue of the B.M.F. Dr. H. Egan and his colleagues describe the results of a survey of the amount of organo-chlorine pesticide residues in human fat and milk in England and Wales. The pesticides investigated were D.D.T. (dichloro-diphenyl trichlorethane), B.H.C. (benzene hexachloride), dieldrin, and their metabolites. This survey is one of several that have been carried out in different parts of the world, including those reported from the Shell laboratories at Sittingbourne. ${ }^{2}$ Dr. Egan and his colleagues' results, which cover the whole of England and Wales, are similar to those of the Shell group, which were for S.E. England only, and the bodies of people living in England and Wales probably contain similar amounts of these compounds to those found in people living in most other European and North American countries.

The amounts of organo-chlorine pesticide residues present in the body are very small. Compounds derived from D.D.T. are most abundant, but even so the total D.D.T.-equivalent is less than $10 \mathrm{mg}$. per kilogram of body fat, and the others are present only to the extent of fractions of a milligram per kilogram of fat. Because of the particular solubility of these compounds in fat this contains much higher concentrations of them than other tissues, in which it would often be difficult to measure any at all.

The source of these insecticides is not known completely, but it is clear that most of them come from the diet, and probably that part of the diet which is of animal origin. The nature of the body fat is conditioned by the composition of the fat in the diet, and when a substance with a high degree of fat solubility enters the body it is natural for it to be stored in the depot fat and secreted in the milk. The higher content of organo-chlorine pesticides in human milk than in cow's milk probably follows from the differences in diet and in the volume of milk produced.
The findings of Dr. Egan and his colleagues and of the Shell group may make some people think that all such pesticides should be banned. Several points must, however, be considered. Firstly, are these pesticides any use ? No one would advocate the indiscriminate use of any pesticide, as it leads to poor control of the pests and needless contamination of the environment. In Britain the use of these pesticides has been carefully considered in successive reports $^{3}{ }^{4}$ by the Ministry of Agriculture, and it is permitted only where there is no practical alternative. The limitations which have been imposed on them are mainly to safeguard wild life, for so far we have very little understanding of the consequences that may follow widespread destruction of it. Secondly, it must be realized that these organo-chlorine compounds are one of the most valuable groups of pesticides, for both agriculture and public health. For the few people who have ever been injured by acute exposure to large amounts there are millions who have benefited from them, and many must owe their lives to them.

Nevertheless, though these chemicals are valuable pesticides, their continued use could not be permitted if the small amounts in our bodies caused us any harm. Fortunately there is no evidence that they do. People with high concentrations of D.D.T. in their fat, a situation that is usually due to occupational exposure, have been observed for long periods and found to remain perfectly well. ${ }^{5}$ The amount of D.D.T. in the fat does not rise indefinitely during continuous exposure, but reaches a plateau that is characteristic for the particular degree of intake. The concentration of D.D.T. in the fat of the general population represents a daily intake that is considerably less than $0.01 \mathrm{mg} . / \mathrm{kg}$. body weight, recently established by the World Health Organization and the Food and Agriculture Organization ${ }^{6}$ as an accepted daily intake for life-long exposure. The acceptable daily intake figure for B.H.C. is $0.0125 \mathrm{mg} . / \mathrm{kg} .^{7}$ The findings of Dr. Egan and his colleagues and the Shell group show that our intake of this pesticide must be well below the acceptable level. Rather less is known about dieldrin and no acceptable daily intake has yet been established by W.H.O. and F.A.O., but, as the groups carrying out these surveys have pointed out, there is no reason to believe that the present levels are in any way harmful.

Surveys of this type are to be encouraged since they form the best guide to the amount of organo-chlorine pesticides in our diet, and a rise in the fat concentrations above their present levels would call for a detailed inquiry. No one wishes to consume more pesticide than he need. Indeed, a further review of the position regarding these pesticides will probably take place in $1968,{ }^{3}$ and this will probably stimulate insecticide manufacturers to seek less persistent materials. However, a compound such as D.D.T. has the undoubted virtues of low cost, safety in use, and effectiveness. Since millions of people must benefit from the use of these compounds it seems likely that we must be prepared to accept some invasion of the privacy of our fat.

\footnotetext{
1 Hunter, C. G., Robinson, J., and Richardson, A., Brit. med. f., 1963, 1, 221.

${ }^{2}$ Robinson, J., Richardson, A., Hunter, C. G., and Crabtree, A. N., Brit. F. industr. Med., 1965, in press.

3 Review of the Persistent Organochlorine Pesticides, 1964. H.M.S.O., London.

- Review of the Persistent Organochlorine Pesticides, Supplementary Report, 1964. H.M.S.O., London.

- Durham, W. F., Residue Reviews, 1963, 4, 34.

- W.H.O./F.A.O. Joint Meeting, Rome, March 1965

7 F.A.O. Meeting Report No. PL/1963/13; W.H.O./Food Add./23 (1964).
} 